\title{
Activating Junior Secondary School Students' Prior Knowledge for the Development of Vocabulary, Concepts and Mathematics through Instructional Strategies
}

\author{
Olu Oyinloye \\ Department of Curriculum Studies \\ Ekiti State University, Ado-Ekiti, Nigeria \\ E-mail: olugaby33@yahoo.com \\ Abiodun.A. Popoola \\ Department of Curriculum Studies \\ Ekiti State University, Ado-Ekiti, Nigeria \\ E-mail: popabiodun2013@gmail.com
}

Received: 10-08- 2013

doi:10.7575/aiac.ijels.v.1n.2p.1
Accepted: 20-09-2013

Published: $31-10-2013$

URL: http://dx.doi.org/10.7575/aiac.ijels.v.1n.2p.1

\begin{abstract}
This paper investigates the activation of students' prior knowledge for the development of vocabulary, concepts and mathematics. It has been observed that many secondary school students are not performing well in the examination conducted by the West African Examinations Council and National Examinations Council of Nigeria. The situation became worrisome because of the dwindling performance of students in English Language and Mathematics which are compulsory subjects for securing admission into tertiary institutions in Nigeria. Four research questions were formulated and translated to test whether a significant difference exist between students' achievement in comprehension in English Language and Mathematics before and after the treatment. The study is a quasi experimental which involves two hundred and sixty students selected through random sampling technique. The experimental sessions lasted six weeks. The experimental groups were engaged in collaborative work in smaller groups where they discussed issues related to the new topics using their prior knowledge. Experimental and control groups were given pre-test before the commencement of the study and achievement test after the experiment. The data collected was subjected to t-test statistics and the findings of the study show that the students in the experimental group performed better than those in the control group.
\end{abstract}

Keywords: Achievement, Comprehension, Semantic mapping, Triangle, Property

\section{Introduction}

Prior knowledge is considered as a very important factor in the teaching and learning process. It is very important to both the teachers and the students. The prior knowledge of the teacher helps him in the lesson delivery because when the teacher has background knowledge of the topic he is handling, he becomes comfortable in the classroom. $\mathrm{He}$ is then capable of drawing information from his prior knowledge to support the new ideas he may wish to teach the students. In this situation, the information at his disposal becomes very robust.

On the other hand, the students' background knowledge is very essential especially when they are learning new concepts. The prior knowledge of the students can help them to understand new lesson especially when they are activated and they serve as pre requisite information. The pre-service and professional teachers should give adequate attention to the prior knowledge of the students. The prior knowledge for the purpose of this study is the sum of a person's previous learning and experience, which will enhance his ability to understand new knowledge or lessons.

The researchers and some lecturers in the Faculty of Education had observed during teaching practice supervision of pre service teachers that most of the pre service teachers failed to activate the prior knowledge of their students. Also it was observed that most of the students in the secondary schools failed to follow the trends of new lesson because their new lessons were not activated. The teachers were not also helping the students to link their prior knowledge with the new lessons. In this situation, the issue of transferring learning could not take place as expected. When students are able to transfer their learning experiences to the new lessons, the lesson becomes interesting and students' achievements become very significant. In almost all school subjects, students' prior knowledge must be activated in order to help the learners to understand the lesson and relate the lessons or knowledge gained to real life situation. 
Prior knowledge when activated in subjects like Mathematics and English language helps in the area of construction of meaning, and understanding of basic concepts. In Nigeria many students are learning English as a second language and they are taught Mathematics in English language which is foreign to them. Some of these students are bilingual or multilingual. They have had contact with their native languages and have learnt to read in the native languages and perhaps do simple calculation in their mother tongue. Students who are able to read and calculate in their mother tongues and in English language have the ability to construct meaning .Those who are taught in English will follow the same process, the only difference is the language structure and culture which developed around its cultural traditions, therefore their prior knowledge needs to receive special attention (Rumelhart, 2004)

On the other hand, students seem to fail Mathematics because they seem not to understand Mathematical language and basic concepts. Also some teachers seem not to link mathematics lessons with the prior knowledge of the students or explain the concept in clear terms that could lead to the understanding of the lessons.

Students are able to learn from texts or lessons only when they can in effect hook what they read or listen to in classroom on something that is already in their background of experience. The term prior knowledge always includes both understanding of concepts contained in the discipline or language used to talk about the concept (Alexander \& Jetton, 2000). Many students could have done better in Mathematics and English language if their prior knowledge were activated.

\section{Statement of the Problem}

It has been observed from our personal experiences and result of discussions with professional colleagues and secondary school teachers during workshops that most teachers do not bother about the prior knowledge of their pupils. At times they only state it in their lesson notes but fail to find out if the prior knowledge of the students is relevant to the new lessons. In this sense, they do not activate the prior knowledge of the students.

\section{Research Questions}

Based on the statement of the problems above, the following research questions were generated.

1. Will there be any difference between the pre-achievement score of students in the experimental and the control groups in English language?

2. Will there be any difference in the post test scores of students in the experimental and control group in English language?

3. Will there be any difference in the pre-test scores of students in the experimental and control group in Mathematics?

4. Will there be any difference in the post test scores of students in the experimental and control group in Mathematics?

\section{Research Hypotheses}

1. There is no significant difference between the pre-test achievement score of students in the experimental and control group in English language

2. There is no significant difference in the post test scores of students in the experimental and control group in English language

3. There is no significant difference in the pre-test scores of students in the experimental and control group in Mathematics.

4. There is no significant difference in the post test scores of students in the experimental and groups in Mathematics

\section{Literature Review}

Prior knowledge is very important in the teaching of Mathematics and English language. A thorough understanding of English language is necessary for the mastery of Mathematics concepts because English Language is the medium of instruction in Mathematics. The importance of prior knowledge especially in literacy learning has been developed through research based on schema theory. Cooper and Kiger (2004) say that the individuals develop a cognitive structure of knowledge in their minds as the individual experiences the world, they add new ideas, and information to the interrelated categories. The mind can be pictured as large system of folders which are capable of storing information in different folders as a result of the individuals' interaction with his environment. The individual therefore adds information to existing schema. The individuals construct meaning from their schemata and build connection among them as the needs arise.

For instance, Mathematical concepts can be taught through semantic mapping strategy. Semantic mapping is a strategy for graphically representing concepts. Semantic maps portray the schematics relations that compose a concept. It assumes that there are multiple relations between a concept and the knowledge that is associated with the concept. Therefore, for any concept there are at least these three types of associations: (i) associations of class, that is, the order of things the concepts fits into; (ii) associations of property, the attributes that define the concept, and (iii) associations of example, that is, exemplars of the concepts. Gunning (2004) says that a semantic map is one type of graphic which graphically shows the relationship between one piece of information and another. Semantic 
mapping can be used to activate prior knowledge and to introduce key vocabulary words. As a post reading activity, words, categories and new concepts can be added to the original maps to enhance understanding.

Semantic mapping can be used to introduce concepts in Mathematics. For instance, different types of triangles and their properties can be introduced through semantic mapping strategy. The diagram below aptly illustrates the use of semantic mapping to teach Mathematics.

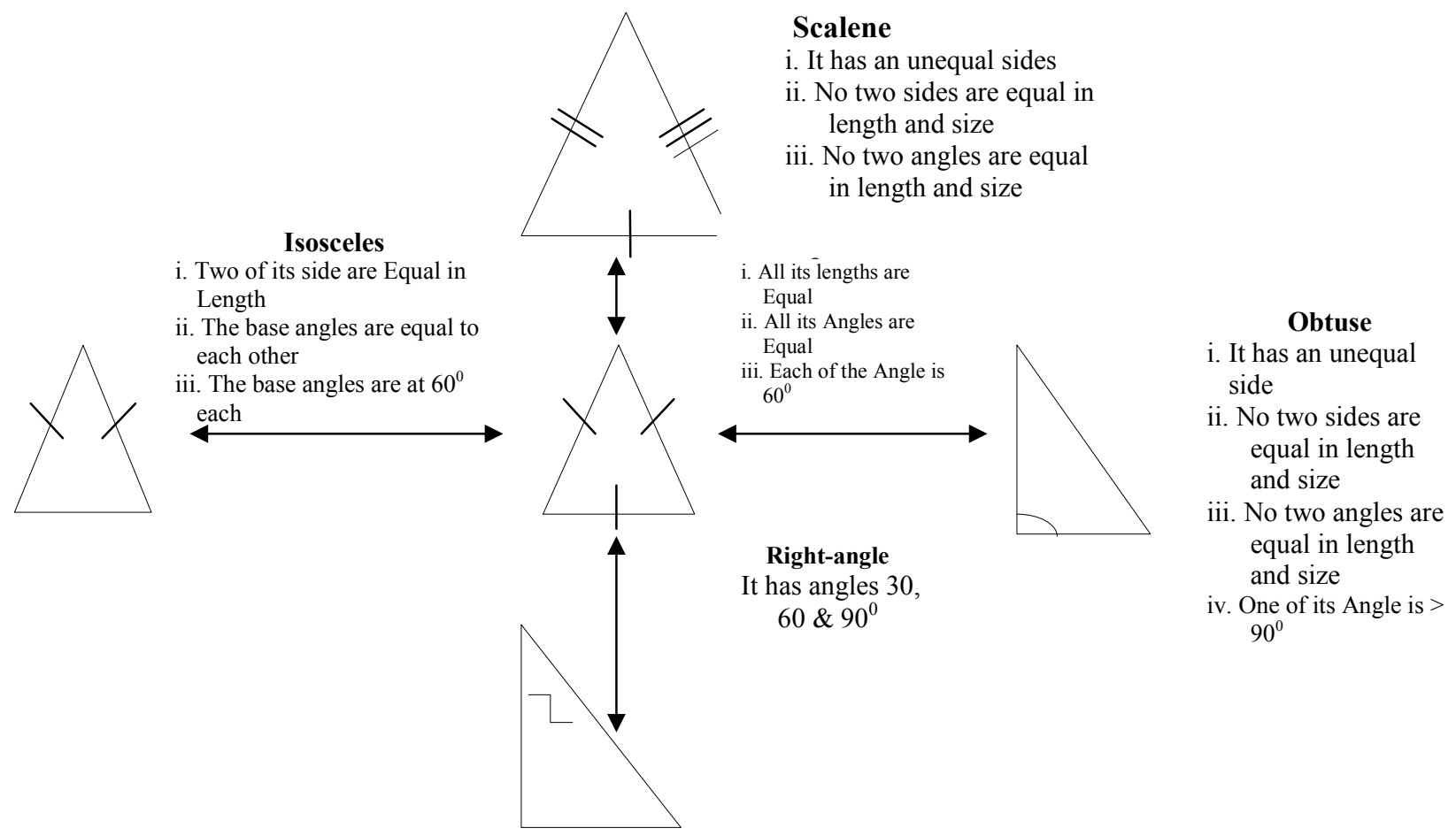

The diagram above shows at a glance the properties of five triangles namely scalene, Isosceles, equilateral, obtuse and right-angled triangle. The students can be led by the teacher to name the properties of each type as the diagrams are presented to the students. The Mathematics teacher can use Semantic mapping to teach mathematics concepts by raising questions that will make students supply answers using their prior knowledge. In reading exercises, such as books, speeches and letters, some students still experience difficulties which made understanding of such materials very difficult. These categories of students will always have difficulty in understanding other subjects like Mathematics, Sciences and the Social Study.

Bulgren, Deshler and Lenz (2007) say that students may experience difficulty due to the variety of text structures found in some primary sources and other expository texts. Factors like lack of clear organisation of materials in a text can hinder the understanding of the text. Homes and Roser (1987) say that what students already knew about a topic is one of the strongest predictors of how well they will learn new information in that topic.

Delapaz and Winston (2007) say that when students encounter new information, those that are actively involved engage in meta cognitive strategies asking themselves questions such as what does this remind me of? This will enable such students to visualize and compare new information. They make connections with what they already knew and consider ways in which new information relates to what they already knew. The implication of this is that the degree to which they call upon their background knowledge and the richness of their background knowledge will play a role in determining the quality of their learning. Background knowledge therefore plays a powerful role in learning in general and reading comprehension in particular. This impact is seen in both literal comprehension and more complex cognitive skills such as making inferences. A sufficient level of background knowledge enhances the ability of students to make inferences while lack of background knowledge compromises students' ability to make sense of a passage. Prior knowledge can aid or hinder new learning, this depends on the individual learners and the way the individuals utilizes the prior knowledge. An individual who can transfer prior knowledge appropriately to new learning could gain more than a learner who misapplied prior knowledge or who has no prior knowledge.

Prior knowledge in specific domains benefits students' learning and achievement; therefore prior learning can enhance students' achievements. Pace, Marshall, Horowitz, Lipson and Lucido, 1989) are of the view that if prior knowledge is inaccurate, incomplete or misleading, it can hinder understanding or learning new information. The implication of this for teaching is that teachers should ascertain that the pre-requisite information possessed by their students are adequate at the commencement of a new lesson especially lessons that aim at developing concept and 
vocabulary among children. Dole, Duffy, Rocher and Pearson (1991) and Ogle (1986) found that inadequate prior knowledge can bring about misconceptions and thereby interfere with the meaning giving to a text.

Nigerian children learn English as a second language after they have acquired their mother tongue before coming to the school. These students are either bilingual or multilingual depending on their exposure to Nigeria languages. These students are proficient speakers of their mother tongues and perhaps learn to read in these languages at the same time they are learning to read and speak English language. Second language learners who have extensive base of prior knowledge that has not been developed around English and cultural traditions of English, needs to receive special attention (Weber, 1991) building and concept development in English language and Mathematics

A technique for accessing the prior knowledge for English language and Mathematics learners has been described as "preview, view and review" (Freeman \& Freeman, 1997). The first stage (preview) is that the teacher aids the pupils to preview the lesson in the child's first language in order to activate first language, background knowledge. The pupils' can discuss the topic with others who speak the same language. The "view portion" is the main lesson, which is taught in English. This will be followed by 'review' where the key concept is taught in the pupils' first language. Pupils can do this in groups and they can report to the teacher for necessary correction. Teachers of literacy should remember the following points according to (Freeman \& Freeman, 1997).

Prior knowledge is crucial to the successful construction of meaning for all learners.

i. Some students will have incomplete or erroneous prior knowledge related to a topic. It is therefore important to assess a students' state of knowledge, if possible before any learning experience.

ii. When students have erroneous or incomplete prior knowledge it is possible to alter it and help them construct meaning more successfully.

Another five techniques for assessing prior knowledge during instruction are:

i. $\quad$ Free recall: "Tell me what you know

ii. Word association: "when you hear the word thief, stolen and detective, or Triangle, Isosceles, equilateral, Scalene what do you do?

iii. Recognition: Display the following key terms (phrases or sentences may be used) and ask students to tell which ones they think may be related to the book they are about to read.

iv. Structured questions: In preparation for reading a particular book, ask the students some questions that will help you to assess their prior knowledge.

v. Unstructured discussion: Tell them that they are about to read about ... (tell them the subject matter e.g. about fishing') what do you know about fishing? (Gunning, 2004).

The above techniques could be used to access the prior knowledge of students. It may be a little bit difficult to know everything about every student's prior knowledge but the teacher will still have a clear idea of what the class knows about the new topic through assessing global knowledge of the students.

Cooper and Kiger (2004) are of the opinion that prior knowledge in reading exercise can be activated through many teaching strategies. Twelve strategies with which teachers can increase students' vocabulary have been identified by. Only two of the strategies will be considered and used in this study: (i) Preview and Predict, and (ii) K-W-L, that is, what I know, I want to learn and what I learned. Preview and Predict strategies had been found to be effective in helping students to construct meaning. Anderson and Pearson (1984) say that the preview and predict strategy is useful when teaching both narrative and expository text as well as Mathematical concepts. It is most effective when students have knowledge of the text and the concepts.

This strategy is useful for second language learners or students who have difficulty in constructing meaning. The teacher has to direct the activities of the students and can also combine the strategy with other methods like discussion. The procedure is that students begin by reading the title, look at pictures where applicable, then decide the type of text whether story or informational. The student will proceed to using their prior knowledge or background experience with information gained during the preview to determine and predict what will happen or what they will learn. Student will proceed to read the text and verify their prediction. The students have to think along with the author as they read, monitoring their prediction and changing it if necessary. Marzano (2004) proposed a strategy known as What I know, I want to know and what I learned. K-W-L strategy is another strategy that can be used for second language learners who study Mathematics. It is useful in activating student's prior knowledge and helping them determine their purpose for studying. It requires students to focus on three questions: two before they read and one after they read. The two before they read are: (i) What I know, K, (ii) What I want to learn L, while the last, which comes after the reading that is (iii) What I Learned. The first two before reading help students to activate their prior knowledge and set their purposes for reading by raising questions they want to answer. The teacher leads students in a discussion of the topic to be read. The students are to write their answers to the question posed before reading after the reading the session. This strategy can be used with students of any age, primary and older students experiencing difficulty in constructing meaning.

Cooper and Kiger (2004) say that the strategy is suitable for initiating a thematic unit because it sets students up to continue to read several selections on a given topic. It is also useful when reading chapters in textbooks in areas such 
as science, social studies or health. This strategy is interactive as it gives students many opportunities to learn from one another. The strategy has been found to help second language learners who are experiencing difficulty in constructing meaning because it immerses them into a natural discussion and offers a strong scaffold provided by teacher support and students' interaction.

\section{Methodology}

The research method adopted for this study is the quasi-experimental pre-test and post test and control group design. It involves administering a treatment to the samples unlike true experiments where participants are not randomly assigned to treatments.

\subsection{Population and Sample}

The population of the study is the junior secondary schools in Ekiti State Nigeria. The samples for the study are 260 students selected from junior secondary schools through stratified random sampling technique. The students were selected from four schools in rural and urban areas.

\subsection{Instrument}

The research instrument for the study is an Achievement Test in English Language and Mathematics. The instrument consists of thirty items of multiple choice questions, which test students knowledge of comprehension on passages read in English Language and solving problems in Mathematics. The questions cover some reading skills such as identification of main ideas, drawing of inference, answering lateral questions, construction of meaning and vocabulary testing. Also, students were tested in algebra, and geometry.

\subsection{Validity and Reliability of Instrument}

The validity of the instrument was established by given the achievement tests to the language education specialist who established the content and face validity. The reliability of the instrument was established through test retest method within the population for three weeks using 40 junior secondary school students who were not part of the study. The samples were divided into experimental and control groups. The experimental groups were exposed to the treatment while the control group was going on with their normal school work. The data collected before and after the treatment were subjected to Pearson Product Moment correlation statistics. A reliability coefficient of 0.74 was obtained which was considered suitable for the study.

\subsection{Research Procedure}

The experiment was carried out within six weeks. The procedure took three forms namely, pre-treatment, treatment and post-treatment stages. The experimental group was allowed to work in groups using the Preview and Predict, and K-W-L-strategies. The control group had no access to these strategies. The achievement tests were administered to both the experimental and control groups before and after the treatment.

\section{Data Analysis}

The data collected was subjected to statistical analysis specifically the t-test statistics. T-test statistics allow researcher to determine whether a difference between groups is significant. All hypotheses were tested at 0.05 level of significance.

\section{Results}

The first hypothesis states that there is no significant difference between the pre-test achievement score of students in the experimental and the control group.

Table 1. Difference in the pre-test achievement score of students in the experimental and the control group

\begin{tabular}{lcccccc}
\hline \multicolumn{1}{c}{ Sources of variations } & $N$ & Mean & Std & $d f$ & $t$-cal & $t$-cal \\
\cline { 1 - 5 } Experimental & 12.807 & 130 & 3.870 & & & \\
\cline { 1 - 3 } Control & 13.369 & 130 & 3.874 & 129 & .982 & 1.96 \\
\hline
\end{tabular}

Significant at 0.05 levels

Table 1 above shows that the $\mathrm{t}$ calculated is .982 while the table value is 1.96 . This implies that there is no significant difference between the experimental and the control group, the null hypothesis is rejected at 0.05 level of significance. This implies that the achievement of the students in the experimental group is not different from that of the control group.

The second hypothesis states that there is no significant difference between the post test achievement score of the experimental group and the control group. 
Table 2. Difference between the post test achievement score of the experimental group and the control group

\begin{tabular}{lcccccc}
\hline \multicolumn{1}{c}{ Sources of variations } & $N$ & Mean & Std & $d f$ & $t$-cal & $t$-cal \\
\cline { 1 - 4 } Experimental & 130 & 22.504 & 4.836 & & & \\
\cline { 1 - 3 } Control & 130 & 14.284 & 3.433 & 129 & -21.62 & 1.96 \\
\hline
\end{tabular}

Table 2 above shows that the t-calculated is -21.62 while the table value is 1.96 , therefore the t-calculated is greater than the table value the null hypothesis is retained at 0.05 level of significance. Therefore achievement of the students in the experimental group is significantly different from that of the control group.

The third hypothesis States that there is no significant difference between the pre test scores of students in the experimental and control groups in Mathematics.

Table 3. Differences in the pre-test scores of students in the Experimental and control groups in Mathematics

\begin{tabular}{lccccccc}
\hline \multicolumn{1}{c}{ Sources of variations } & $N$ & Mean & Std & $d f$ & $t$-cal & $t$-value & $R$ \\
\cline { 1 - 4 } Experimental & 130 & 12.805 & 3.865 & & & \\
\cline { 1 - 3 } & 130 & 13.356 & 3.865 & 129 & .979 & 1.96 \\
\hline
\end{tabular}

Table 3 above shows that the t-cal is .979 while the table val. is 1.96 . The null hypothesis is therefore rejected. This implies that there is no significance difference between the experimental and the control group.

The fourth hypothesis states that there is no significant difference between the post-test scores of students in the experimental and control groups in Mathematics.

Table 4. Differences between the post-test scores of students in Mathematics

\begin{tabular}{lccccccc}
\hline \multicolumn{1}{c}{ Sources of variations } & $N$ & Mean & Std & $d f$ & $t$-cal & t-value & $R$ \\
\cline { 1 - 3 } Experimental & 130 & 11.800 & 1.98 & & & \\
\cline { 1 - 2 } Control & 130 & 10.769 & 1.45 & 229 & -6.38 & 1.96 \\
\hline
\end{tabular}

Table 4 above shows that the $\mathrm{t}$-cal is -6.08 while the table value is 1.96 . This implies that the $\mathrm{t}$-calculated is greater than the table value. The null hypothesis is therefore retained at 0.05 level of significance. This implies that the achievement of the students in the experimental group in Mathematics is significantly different from that of the control group.

\section{Discussion}

The primary objective of this study is to assess the effect of student's prior knowledge on activating and developing vocabulary concepts in Mathematics and English Language among junior secondary school students. From the results of the findings, the analysis of hypotheses one and three as shown in tables 1 and 3 revealed that students in the experimental and the control groups were homogeneous at the beginning of the experiment. Their levels of achievements did not vary significantly in vocabulary and concepts in Mathematics and English Language. The results of the analysis of the data collected in respect of hypothesis two and four which tested whether differences existed between the students post-test achievement scores in the experimental groups in vocabulary concepts in English language and Mathematics respectively showed that remarkable significant differences existed.

The students in the experimental groups in both Mathematics and English Language had higher gains in terms of achievement than those in the control group. This implied that the treatment was effective. The high achievement of students in the experimental groups in Mathematics and English indicate the effectiveness of the activation of students' prior knowledge which perhaps led to the understanding of the new lesson. This shows how important it is to assess the students' prior knowledge before any learning experience. A critical study of the performance of the students in the experimental groups and control group in the area of comprehension, Mathematics vocabulary building and construction of meaning shows that the students whose prior knowledge was linked with the learning experience in the two teaching strategies used for the experimental group had higher achievements than those student in the control group.

The preview and predict strategy is very effective in helping students to construct meaning especially when reading narrative and expository texts and mathematics. The finding of the study corroborate the gains of preview and predict strategy as propounded by Alexander and Jetton (2004). Also, the various strategies recommended by Freeman and Freeman (1997), Gunning (2004) and Marzano (2004) have been found useful in this study as good means of activating students prior knowledge, which could enhance their achievements in vocabulary building and understanding of concepts in English language and Mathematics. The difference in the performance of students 
whose prior knowledge were accessed and those whose were not accessed further supports the fact that the degree to which students call upon their background knowledge and the richness of their background knowledge will play a role in determining the quality of their learning.

What students already know about a topic is one of the strongest predictors of how well they will learn new information in a particular subject area. Homes and Roser (1987) were of the view that what a student already knew determines how well he learns new information. Reading is more difficult when students are not familiar with the vocabulary which creates challenges for them. The problem may be compounded when the students' prior knowledge is not activated because there will be no link between the student's prior knowledge and new lesson. This buttressed the low achievement of students in the control group in this study whose prior knowledge were not activated, hence their achievement was not as high as those students in the experimental group.

\section{Conclusion}

The findings of the study have justified the need to access and assess the students' prior knowledge before exposing them to new learning experience. Findings from the study have shown that the students will gain a lot when they are helped to relate their prior knowledge to the new learning situation. The strategies discussed in this study could be used to assist students in other disciplines such as sciences, Arts and Social science to mention a few.

\section{Recommendations}

As a result of the findings of this study, it is recommended that language and Mathematics teachers as well as teachers in other disciplines should take the advantages of using K-W-L strategy discussed in this study to activate the prior knowledge of their students. Second language and Mathematics learners should be helped to tap their prior knowledge in order to learn new skills in such a way that learning will be interesting. Prior knowledge can serve as incentive for learning new concepts constructing meaning when reading as a second language learner.

\section{References}

Alexander, P. A. \& Jetton, T. L. (2000). Learning from Text. A Multidimensional and Developmental Perspective. In M. L. Kamil, P. B. Mosenthal, P. D. Pearson \& R. Bair (Eds) Handbook Of Reading Research. (3): 255-310. Anderson, R. C. \& Pearson, P. D. (1984). A Schematheoretic View of Basic Processes in Reading comprehension" in Pearson P.D. (Ed) Handbook of Reading Research. New York: Longman. 225-291.

Bryatt, D. P.; Godwin, M.; Bryant, B. R. \& Higgins, K. (2003). Vocabulary instruction for students $\quad$ with learning disabilities. A Review of the Research Learning Disabilities. Quarterly. 26(2): 117-128.

Bulgren, J.; Deshler, D. D. \& Lenz, B. K. (2007). Engaging adolescents with LD in higher order thinking about history concepts using integrated content enhancement routines. Journal of Learning Disabilities. (40): 121-133. Cooper, J. D. \& Kiger, N. D. (2004). Literacy Helping Children Construct Reading. New York: Houghton Mifflin Company.

Delapaz, C.; Morales, P. \& Winston, P. M. (2007). Source interpretation: Teaching Students with and without LD. to read and write historically. Journal of Learning Disabilities. (40): 134-144.

Dole, J. A.; Duffy, G. G.; Rochler, L.R \& Pearson, P. D. (1991). "Moving from Old to the New. Research on Reading Comprehension Instruction". Review of Educational Research 61, Pp 239-264.

Freeman, Y. S. \& Freeman, D. E. (1997). Teaching reading and writing in Spanish in the bilingual classroom. Portsmouth: Heinmann.

Gunning, T.G. (2004). Creating literacy Instruction for all children. Boston: Allyn \& Bacon.

Homes, B. C. \& Roser, N. L. (1987). Five ways to assess reader's prior knowledge. The Reading Teacher. 40: 646647.

Marzano, R. J. (2004). Building background knowledge for academic achievement. Association for Supervision and Curriculum Development. Alexandria.

Ogle, D. M. (1986). A teaching model that develops active reading of expository text. The Reading Teacher. 396: $564-570$.

Pace, A. J.; Marshall, N.; Horowitz, R.; Lipson, M. Y. \& Lucido, P. (1989). 'When Prior Knowledge Doesn't Facilitate

Text Comprehension. An Examination of Some of the Issues'. In The Thirty-Eight Yearbook of the National Reading Conference, Cognitive and Social perspective for Literacy Research and Instruction The National Reading. 213224. Chicago.

Ross, A. T. (2004). Academic aptitude and prior knowledge as predictions of students achievement: Introduction to psychology. Journal of Educational Psychology. 96(4): 778-784.

Rumelhart, D. E. (2004). The building blocks of cognition. In R. J.Spiro et al (Eds) Theoretical Issues in Reading Comprehension. N. J. Lawrence Erlbauin Association Hillsdate. 33-58

Weber, R. (1991). Language diversity and reading in American Society. In R. Barri, M. L. Kamal, P. Mosenthal \& P. D.

Pearson (Ed) Handbook of Reading Research. New York: Longman. 97-119. 